\title{
THE GREAT CHAIN METAPHOR: AN OPEN SESAME FOR PROVERB SEMANTICS?
}

\author{
$\underline{\text { Arvo Krikmann }}$
}

In "Metaphors We Live By" (1980) G. Lakoff and M. Johnson engrafted a new, nowadays wellknown branch on the theory of metaphor. In "Women, Fire and Dangerous Things" (1987) Lakoff investigated the cognitive models people use when understanding and categorizing the world, and the role of metaphor and metonymy in these models. In "More than Cool Reason" (1989) Lakoff and Mark Turner developed the cognitivistic theory of metaphor in various aspects. In "The Invariance Hypothesis" (1990) Lakoff supposed that the most part of abstract reasoning happens via metaphorical mappings, and many of the most basic concepts in semantics (e.g. time, quantity, state, change, action, cause, purpose, means, modality, and even category) are also understood metaphorically.

In "More than Cool Reason" Lakoff and Turner come across the eternal paremiological problem: in what way do people understand figurative meanings of proverbs? To solve this problem they propose the tool termed the GREAT CHAIN METAPHOR (further: GCM) - a cognitive apparatus consisting of four ingredients:

1) the naive theory of the Nature of Things (further: TNT);

2) the Great Chain of Being (further: $\underline{\mathrm{GCB}}$ ) qualified as a cultural model;

3) the GENERIC IS SPECIFIC metaphor (further: GISM);

4) the Maxim of Quantity (further: MQ).

My paper intends to make some critical remarks on GCM.

\section{GCB + TNT, and MQ}

GCB is alleged to be a largely unconscious cultural model which places all the things and beings as well as their properties on a vertical scale and thus divides them into "lower" and "higher" ones. The lowest level is occupied by inanimate substances and things, the next level above by plants, the next one by animals, and the highest level by human beings. (In its extended version GCB also includes such "higher than highest" levels as society, God, and the universe.) An object of any level has all the properties of any lower level and, in addition, its "own" highest level properties which determinate this concrete level and are lacking at any lower level. The higher the level, the more ranks of properties an object has. So, a human being has physical + biological + instinctual attributes and behavior + specific highest-order features like intellect, moral, aesthetic sense, etc.

GCB-model does work, without doubt, in proverb semantics. However, Lakoff and Turner leave it vague how it works, which restrictions are involved, and so on. Let us list some of the main contradictions.

1. On the one hand, Lakoff and Turner stress repeatedly that the distinction "human / non-human" is very strongly marked in the semantics of proverbial metaphors. More precisely, human beings, relations and problems constitute the most typical target domain of paremic metaphors, or "actual themes" of proverbs. To be still more exact, it is just specifically human (intellectual, ethical, social) 
problems that are most often dealt with in proverbs. All this appears absolutely valid, and paremiologists have discussed the same topics during the past 20 years. (However, one could ask which maxim is applied "to pick out the highest-ranking properties available in each situation" (p. 173) - is it MQ or, for example, the Maxim of Relevance?)

2. On the other hand, at the same time Lakoff and Turner assert that GCB actually works in both directions: "it allows us to comprehend general human character traits in terms of well-understood nonhuman attributes; and conversely, it allows us to comprehend less well-understood aspects of the nature of animals and objects in terms of better-understood human characteristics" (p. 172). The paradox is that this assertion is also absolutely true - but it is sharply incompatible with what was said above.

3. Sometimes, particularly in the analysis of "Big thunder / little rain" one can get the impression that despite of everything said in (1) and (2) GCB is still a homogeneous network acting monotonously between all its levels and knots and enabling transfers from anything to anything without any restrictions, even at one and the same level. For example, "Big thunder / little rain" "might be applied to a viciously barking dog, as a way of saying that there's no reason to be afraid of him" (p. 179); or it "works in pretty much the same way as the English proverb 'All bark and no bite' with the only difference that 'All bark and no bite' cannot be applied metaphorically to dogs, but it can be applied metaphorically to thunderstorms" (p. 180); or it might be used in "a situation in which an earthquake has just made a large rumbling noise /../ to indicate that the earthquake won't cause much damage" (p. 179). Of course, such exceptional uses may happen, but I do not believe that they represent the normal working routine of proverbial metaphors.

To get a more verified notion of what is frequent / allowed or rare / excluded in the metaphorics of proverbs we should have a considerable amount of direct data about proverb actualizations - much more than paremiologists or others have at their disposal. Therefore I would dare to hypothesize here merely some roughest rules that I believe to govern the relations of words and meanings in proverbs.

Rule 1. Example: "Everything has its beginning and end".

If anything that acts or happens literally in the proverb belongs to the "specifically human" (intellectual, ethical, social, abstract) sphere then the metaphorical reading of the text is, on the principle, impossible.

\section{Rule 2. Example: "Like bird, like song".}

If both the literal referents (agents, objects, etc.) and their literal predicates (properties, actions, interrelations, etc.) are of non-human rank, the mixing of these non-human GCB-levels is avoided. Such texts are already literally meaningful (semantically compatible, "smooth") and result in sentential metaphors (G. A. Miller's term) that must be understood as sayings about people.

Rule 3. Example: "Who digs a pit for another, shall fall therein himself".

If human beings participate somehow in the literal content of a proverb - either as immediate actants, or impersonal "addressees" of imperatives, or otherwise -, and the rest of the literal content includes some lower-order-human or non-human components (e.g., biological traits, animals) then 
the necessary minimum of those lower-order or non-human constituents must be reinterpreted into the highest-order and/or human.

Rule 4. Examples: "A lie has short legs"; "A man cannot fly higher than his wings enable"; "The man is a wolf"; "Your own eye is the king".

If the text in its literal plan is semantically "broken" (contradictory, incompatible) then the contradiction may be liquidated in any suitable direction. Miller's predicative and nominal metaphors are the simplest representatives of this case. When the actual context is absent, there is a strong tendency to read the beginning of the contradictive text as semantically "open" (literal) and the predicative part as "hidden" (figurative); nominal metaphors evidently allow only such reading.

As to the actual meanings the rules look something like this:

Rule A. Denomination is one-sided: when a proverb intends to say something about human beings, they may be called just men, or animals, plants, things, etc., but the contrary is impossible: animals, plants, things and other non-human referents must be denominated with their "right" names, not via human metaphors.

Rule $B$. Predication is many-sided: it is possible to predicate metaphorically something non-human to a human being or vice versa, something physical to an abstract object, and so on.

\section{GISM}

When dealing with metaphors cognitivists operate neither with term: term (or concept: concept) nor sentence: sentence, but schema: schema relationships. In the case of proverbial metaphors three types of schemas are involved:

1) the specific-level schema representing the source domain (i.e. the literal content of the proverb);

2) the specific-level schema representing the target domain (i.e. the content the user actually wants to put into the proverb);

3) the generic-level schema mediating the transition from the specific source to the specific target.

In its essence the generic-level schema is evidently nothing else but the semantic common part between what was literally said in the text and what was actually intended to be conveyed. Otherwise, generic-level schema is a kind of abstract-termed expression (or "bundle of thoughts"?) characterizing the semantic capacity, or "interpretational potential" of the proverb.

Pertaining to the essence of GISM as the whole, Lakoff and Turner put it as follows: "There exists a single generic-level metaphor, GENERIC IS SPECIFIC, which maps a single specific-level schema onto an indefinitely large number of parallel specific-level schemas that all have the same genericlevel structure as the source-domain schema" (p. 162).

Now let me list some questions and doubts provoked by the concept of GISM. 
1. It is hard to conceive the relationship between the generic and specific as a metaphor even in "Lakoff's spirit": his metaphors work, as a rule, "horizontally", mapping the specific onto specific or the generic onto generic, whereas here the connection is overtly "vertical". Hence the more general problem will arise: which metaphor do the very parameters "horizontal" and "vertical" come from? ABSTRACT AND/OR CAPACIOUS CONCEPT IS HIGH / CONCRETE AND/OR CONTENTFUL CONCEPT IS LOW (AND WIDE?)? Or, the usual metaphorical mappings of conceptual hierarchies being remembered, perhaps they come from a still more "generic" one, say, OUR CONCEPTUAL SYSTEM IS A PILE? But as the "world of concepts" appears to be successfully juxtaposable with the "world of material things", it could be understood as if it were an independent semantic domain and we might have a good reason to ask: what would be wrong if one preferred to interpret this alleged metaphor as a metonymy, a kind of "conceptual synecdoche", say, SPECIFIC STANDS FOR GENERIC?

(Many other analogous questions might be asked, for example, does there exist one integral "world of modalities", or must they be kept separately? However, it is again considerably hard to interpret things like rhetorical questions, irony, "prognosis-formed" orders and interdictions, etc. as modal metaphors; it seems much more natural to speak about metonymies like QUESTION STANDS FOR NEGATION; QUESTION STANDS FOR REPROACH; QUESTION STANDS FOR IMPERATIVE; APPROVAL STANDS FOR CONDEMNATION; PROGNOSIS STANDS FOR ORDER, etc.)

2. The generic-level schema has to perform two evidently incompatible tasks in GISM: 1) serve as a mediator between the literal and really intended meaning in the case of each single actualization of a proverb;

2) sum up the information about the total semantic scope of a proverb exhausting all the traditional and possible meanings it has or can get.

3. As to the task (1) GISM as a metaphor appears to be conceptually defective and insufficient to link together (map onto each other) the specific-level source and the specific-level target, because the generic-level component of GISM is also target. To reach the aim the "mediating target" should be somehow related to the "final target", but we get no idea what kind of relation it might be and how it could be termed, also what onto what this operation would map, and so on. (Actually, it is also impossible to interpret the two operations involved in this process of analogygrasping as two oppositely directed metonymies. In order to say that X STANDS FOR Y, this X should be necessarily put into words. Here the only necessarily verbalized thing is the proverb. Therefore it seems quite natural to say that (VERBALIZED) SOURCE-SPECIFIC STANDS FOR (THOUGHT) GENERIC. But what "stands" for what when the thoughts induced by signals of nonverbal rank and the thoughts induced by words are being related? What kind of signs should we use in our metalanguage to put all this together? Do the proverbial metaphors altogether differ from the rest of metaphors significantly enough to motivate the introduction of GISM-concept just on the occasion of proverbs, and not in general?)

4. As to the task (2) GISM can hardly solve any of the related fundamental problems long ago recognized and researched in paremiology. For example, natural actualizations of a proverb in different situations (as well as its context-free interpretations) can be regarded not merely as differing in meaning, but also as more effective (exact, apt, striking) or more inefficient ("loose", 
inept, clumsy, even failing). (The problem has been discussed by R. Honeck and his colleagues.) If they all are being generated by means of one and the same generic-level schema, the schema ought likely to be something too abstract and contentless to retain 1:1 relationship just with a concrete proverb. Further, natural proverb stocks include numerous, sometimes quite long series of entirely or partially synonymous proverbs - what about their generic-level schemas? Do some of them share some schemas? or has each its own? or something else? Finally, one can ask, is it altogether reasonable to speak about a certain definite "generic level" people use to decode proverbs? Contextbound actualizations are rather understood via minimal necessary changes, whereas "semantic emptying" of a context-free proverb can be carried out step by step in various directions, having its "raw" literal meaning on the one end of the scale and some ultimately contentless expressions like G. Permiakov's "invariants" or Z. Kanyo's formula $\forall x[P(x) \supset Q(x)]$ on the other.

\section{SOME OTHER PROBLEMS}

To the authors' mind, proverbs are metaphorical descriptions of certain situations. This comes very close to G. Permiakov's opinion that proverbs are nothing else but signs of situations. There are several different ways to distinguish proverbs from the "lower forms of phraseology". Permiakov, for example, uses a "softer" criterion: proverbs are syntactically closed, proverbial phrases are open. Z. Kanyo has postulated that proverbs are generalized implications (cf. the formula above), i.e. share their logical form with expressions representing laws. If the "soft" criterion is used, a part of proverbs will certainly appear to be descriptions. In "1001 Frage..." I tried to demonstrate that Kanyo's "hard" criterion works in a sense much better than the "soft" syntactic criterion. But anyway, the bulk of proverbs does represent a kind of empiric laws (i.e. generalizing assertions) or norms (i.e. generalizing imperatives), and therefore their relationships with situations (in the sense of everyday situations, or communicative contexts, not cognitive schemas) are much more complicated than those of descriptions. Situations serve merely as "topical inductors" for proverbs. Proverbs derive prognoses, explanations, appraisals and prescriptions from situations.

Lakoff and Turner admit that proverbs may accidentally imply exhortations. They also note that "proverbs are always understood relative to a background of assumptions and values, and with different backgrounds the same metaphor can lead to very different interpretations" (p. 187), and they give an excellent meditation about possible referential and axiological interpretations which the phrase "Jelly in a vise" might get in different contexts. But they do not interpret assertions, appraisals and exhortations as links of some integral "Great Chain of Pragmatical Being". Neither do they notice the exclusive importance of the good/bad-link in the functioning of that chain.

Last but not least, I would like to draw attention to some more general facets in Lakoff's metaphor theory.

Firstly, Lakoff's metaphor paradigms (like the largely cited LIFE IS A JOURNEY, or PEOPLE ARE PLANTS, or A LIFETIME IS A YEAR, etc.) resemble pretty much Permiakov's invariants. Their common feature is that both have been alleged not to intersect, at least not on the principle. Actually they do intersect, or display logical part-whole relationships, and the greater amount of them we will invent, the more obvious this danger will become.

There exists another very fundamental problem which concerns interrelations of source and target concepts in the metaphor and which has been noticed earlier, especially in connection with Lakoff's 
Invariance Hypothesis (e.g., by C. Brugman, T. Onikki and U. Nikanne). If the major part of abstract matters is mapped (i.e. not merely termed but also thought) metaphorically, the corresponding target domains should likely be lacking of independent "a priori" conceptual structure, and consequently, there would be no reason to speak about analogies between source and target concepts, GENERTIC IS SPECIFIC metaphors, and so on.

\section{Note:}

Published in: Proverbium 11 (1994), pp. 117-124.

\section{References}

Kanyo, Zoltan 1981: Sprichworter - Analyse einer Einfachen Form. The Hague: Mouton.

Krikmann, Arvo 1984: "1001 Frage zur logischen Struktur der Sprichwörter." Semiotische Studien zum Sprichwort. Simple Forms Reconsidered 1. Eds. Peter Grzybek and Wolfgang Eismann.

Tübingen: Gunter Narr, pp. 387-408.

Lakoff, George 1987: Women, Fire, and Dangerous Things. What Categories Reveal about the Mind. Chicago: University of Chicago Press.

Lakoff, George \& Johnson, Mark 1980: Metaphors We Live By. Chicago: University of Chicago Press.

Lakoff, George \& Turner, Mark 1989: More than Cool Reason. A Field Guide to Poetic Metaphor. Chicago: University of Chicago Press.

Permiakov, Grigori 1970: Ot pogovorki do skazki (Zametki po obschei teorii klishe). Moskva:

Nauka. Also published in English translation by Y.N. Filipov with the title From Proverb to FolkTale. Notes on the General Theory of Cliche. Moscow: Nauka, 1979. 